\title{
Hypotrichosis-intellectual disability, Lopes type
}

INSERM

\section{Source}

INSERM. (1999). Orphanet: an online rare disease and orphan drug data base.

Hypotrichosis-intellectual disability, Lopes type. ORPHA:2266

Hypotrichosis-intellectual disability, Lopes type is characterised by hypotrichosis,

syndactyly, intellectual deficit and early eruption of teeth. It has been described in two patients. The mode of transmission appears to be autosomal recessive. 